Published by the University of KwaZulu-Natal https://journals.ukzn.ac.za/index.php/JICBE (C) Creative Commons With Attribution (CC-BY)

Journal of Inclusive cities and Built environment. Vol. 2 Issue 1

How to cite: N. Chanza. 2022. Prospects of Twinning Climate Change and Urban Sustainability Issues through Transformative Adaptation: Lessons for African Cities. Conference Proceedings for International Symposium on Inclusive-Cities: Achieving Inclusive Cities Through A Multidisciplinary Approach, 2021 28-30 June. Journal of Inclusive cities and Built environment. Vol. 2 Issue 1, Pg 65-69.

\title{
PROSPECTS OF TWINNING CLIMATE CHANGE AND URBAN SUSTAINABILITY ISSUES THROUGH TRANSFORMATIVE ADAPTATION: LESSONS FOR AFRICAN CITIES
}

\section{By N. Chanza}

Published 31 January 2022

\begin{abstract}
In most African cities, existing approaches to tackle climate change and sustainability issues have remained largely weak, piecemeal and fragmented. For example, current adaptation practices are mainly focusing on 'adapting to' climatic disturbances instead of 'adapting with' the vulnerable urban population. This approach views climate change as the main source of vulnerability and focuses on protecting systems from weather and climatic events. It grossly ignores the social roots of vulnerability and misses out on opportunities such as those that emerge when climatic risks are jointly treated with environmental sustainability concerns. To evade this problem, this paper proposes a shift towards transformative adaptation, an approach that comprehensively attend to the entire urban socio-ecological system. The aim is to contribute to the discourse of inclusive cities by examining the prospects of simultaneously addressing climate change alongside other urban development challenges. Drawing on growing literature and reports on climate change adaptation in cities, I argue that the adjustment approach does not comprehensively address the underlying urban vulnerabilities and fail to match the severity of climate change impacts being experienced. On the contrary, a transformative approach locates urban risk beyond the biophysical environment to the entire urban socialecological system. Thus, this approach is capable of jointly dealing with climate change and other urban development challenges as it holistically deals with the underlying vulnerability risks in urban settlements while addressing the root causes of urban unsustainability. African cities can draw useful lessons from the benefits that come with a transformative adaptation trajectory.
\end{abstract}

KEY WORDS Adaptation, Climate change impacts, Urban transformation, Urban poverty, Vulnerability.

Nelson Chanza: Department of Urban and Regional Planning, University of Johannesburg, Johannesburg, 2006, South Africa nchanza@gmail.com 


\section{INTRODUCTION}

The intersection of climate change and underlying urban development challenges remains complex and vexing, particularly to African cities. Climate change is exacerbating existing urban development issues, posing a challenge to efforts towards the attainment of sustainable human settlements [1]. There is now growing acknowledgement that climate change imposes pressure on urban sustainability [2-4]. In particular, understanding the implications of a warmer world is necessary to transit from adaptive capacity to transformative capacity [5]. However, positioning cities in global climate action has received mixed attention and the approaches used remain heterogenous. In most African cities, existing approaches to tackle climate change and urban sustainability issues have remained largely weak, piecemeal and fragmented [6]. This is because climate change has not been fully mainstreamed in urban development and the adaptation pathway being pursued concentrates on climate change as a source of vulnerability and fails to recognise other deep-rooted nonclimatic sources of vulnerability.

As the urban inclusivity agenda unfolds, critical questions that ought to be addressed relate to: a) How adaptation plans impact marginalised people, particularly people living in informal settlements? b) Whose resilience are adaptation interventions targeting? These questions require a shift from traditional to new adaptation approaches. Traditional adaptation practices tend to mainly focus on 'adapting to' climatic disturbances instead of 'adapting with' the vulnerable urban population [3]. The former looks at climate change as the main source of vulnerability and focuses on protecting systems from weather and climatic events, while the later assumes that sites of adaptation are integrated within the entire socioecological system [3,5,7]. Proponents of the 'adapting to' trajectory have been accused of missing out on opportunities such as those that emerge when climatic risks are jointly treated with environmental sustainability concerns. This pathway involves hurried responses to climate change external stimuli and ignores internal urban processes (e.g., urbanisation, migration, urban poverty and pandemics) that expose people to climatic risks. Depending on the course of action pursued, climate change can be both an opportunity and a threat to urban sustainability. However, if adaptation practices are hastily executed, they are likely to miss on opportunities to address underlying non-climatic drivers of vulnerability, which lead to sustainable development failures.

This paper locates itself within the matrix of these notions (climate change adaptation and urban sustainability) and applies them to understand how cities in Africa can transit towards a sustainable pathway in the face of climate change. The study contributes to the discourse of inclusive cities in a context of climate change challenges by interrogating the prospects of jointly treating climate change with other underlying urban sustainability issues. The focus of the study is on African cities where the combined effects of climate change and sustainable development problems create high risks for most poor urban communities. First, the study conceptualises these terminologies in order to establish a theoretical foundation to situate the argument. Second, it draws experiences and lessons from adaptation practices adopted by selected African towns and cities. Third, it highlights opportunities and challenges that these towns and cities experience as they mainstream climate change issues into their urban development agendas.

\section{LIMITATIONS OF TRADITIONAL ADAPTATION APPROACHES}

Responses to growing changes in urban socio-ecological systems are characterised by terminologies such as adaptation, resilience, sustainability, and transformation [5]. Adaptation involves responses of natural and human systems to climatic stimuli. The purpose of adaptation is to build adaptive capacity or make communities resilient against climatic disturbances. Robust adaptation interventions are required to build resilient urban communities. The history of adaptation practice shows that adaptation responses have largely failed to address deep- rooted urban development issues that hinder transitions towards resilient and sustainable cities [5]. The existing adaptation trajectories are inadequate in terms of reducing ecological and social vulnerabilities and enhancing resilience [6]. Traditional response approaches limit their focus to tangible, biophysical impacts of climate change. Accordingly, focus is now shifting towards transformative adaptation.

\section{IS TRANSFORMATIVE ADAPTATION THE ANSWER FOR AFRICAN CITIES?}

Climate change modifies interactions in human settlement systems and calls for appropriate adaptation trajectories that provide long term and sustainable benefits [8]. There is now growing acknowledgement that adaptation planning needs to embrace justicesensitive approaches to address existing vulnerabilities and avoid maladaptive and conflicting outcomes [3]. Transformative adaptation is considered essential to enable system change rather than relying on incremental adaptation that falls short of providing the desired sustainable trajectories [5]. It moves from merely responding to the challenges to shaping them (Table 1). This approach aims to extend benefits and synergies with other broader urban development goals [7]. It is intended to deal with severe climatic risks and vulnerabilities across the entire socio-ecological system. 
Table 1: Comparing traditional and transformative adaptation approaches.

\section{Traditional approaches}

Driven by the need to adapt to climatic events

Focuses on climate change as the main source of vulnerability

Focuses on protecting systems from weather and climatic events

Responses usually hurried or incremental

Ignores internal urban processes (e.g., urban informality, migration, urban poverty, pandemics) that expose people to climatic risks

Misses out on opportunities - when climatic risks are jointly treated with environmental sustainability

The sustainability of this trajectory is questioned

\section{Transformative Approaches}

Driven by the need to adapt with vulnerable populations

Focuses on underlying drivers of climatic risks

Assumes that sites of adaptation are integrated with the entire socio-ecological system

Proactive responses

Integrates internal process within the entire urban socio-

ecological system

Gains on benefits from joint treatment of climatic risks with other development challenges

Follows a sustainable pathway

Clearly, by focusing attention to the entire urban socio-ecological system, the transformative approach has potential to address the underlying inherent urban development challenges that are common among the poor and vulnerable populations in Africa.

\section{ADAPTATION EXPERIENCES IN AFRICAN CITIES}

African cities face a combination of multiple climatic risks and urban development challenges that require urgent holistic interventions (Table 2).

Table 2: Selected African cities facing climatic and urban development issues.

\begin{tabular}{|c|c|c|}
\hline City & Urban Development Issues & Climatic Issues \\
\hline Bulawayo, Zimbabwe & $\begin{array}{l}\text { High unemployment; obsolete water and sanitation } \\
\text { infrastructure leading to sewage bursts and water-borne } \\
\text { diseases; water, energy and food insecurities. }\end{array}$ & Water stress; drought; heat waves \\
\hline $\begin{array}{l}\text { Cape Town, South } \\
\text { Africa }\end{array}$ & Urban informality and crime, urban inequality and poverty. & Water stress, floods, sea level rise \\
\hline Dar es Slaam, Tanzania & $\begin{array}{l}\text { Water access challenges; large share of population in } \\
\text { informal unserviced settlements; urban poverty; urban } \\
\text { sprawl and expanding informal settlements; food security } \\
\text { challenges. }\end{array}$ & Water stress, floods, sea level rise \\
\hline Cairo, Egypt & $\begin{array}{l}\text { Water stress and water-use conflicts; rapid population } \\
\text { growth; food insecurity. }\end{array}$ & Water stress; drought; heat waves \\
\hline Beira, Mozambique & $\begin{array}{l}\text { Water and sanitation challenges; poorly planned and } \\
\text { unserviced settlements }\end{array}$ & Water stress, floods, sea level rise \\
\hline Nairobi, Kenya & $\begin{array}{l}\text { Rapid urbanization; water and sanitation challenges; } \\
\text { urban informality; high crime }\end{array}$ & Water stress, floods, heat waves \\
\hline Lagos, Nigeria & $\begin{array}{l}\text { Rapid urbanization, water and sanitation challenges, high } \\
\text { unemployment, high crime }\end{array}$ & $\begin{array}{l}\text { Water stress, floods, sea level rise, } \\
\text { heat waves }\end{array}$ \\
\hline
\end{tabular}

Source: $[9,10]$ 
Despite promises of transformative adaptation benefits, experiences of many African cities show that this adaptation pathway may be difficult to implement owing to several reasons. These can be summarized as:

Uncertainties about climate risks and adaptation benefits. For example, in Zimbabwe, previous known climatic risks tended to be in low lying areas and large cities with high vulnerable populations concentrated in informal settlements. However, the experiences with Cyclone Idai has shown that even mountainous settlements were vulnerable to flooding. Chimanimani, a mountainous small town in Zimbabwe was hard hit by the Cyclone Idai since there were no strong mechanisms to withstand the impacts.

- The perceived high cost of transformational actions where most cities in low income countries are not ready to allocate budgets towards holistic programmes that address the socio-ecological challenges of the city. As a result they only think about allocating funds when the disaster is already felt. For example, Beira in Mozambique has been facing repeated outbreaks of waterborne diseases associated with frequent flooding.

Institutional and behavioural actions that tend to maintain existing policies and regimes, which leads to perpetuation of a status quo. A growing number of cities in Africa have acknowledged the existence of climate change but they seem not to have capacity to address it.

\section{CONCLUSION}

African cities face multiple challenges from the combined effects of climate change and urban development challenges that threaten their sustainability. This paper has proposed that the transition from traditional incremental adaptation practice to transformative adaptation regimes can help to address these twin challenges as it holistically attend to the entire socioecological system of cities. If adaptation practices are hastily executed, they are likely to miss on opportunities to address underlying non-climatic drivers of vulnerability, which lead to sustainable development failures. Traditional adaptation approaches fail to match the severity of climate change impacts being experienced or anticipated. Accordingly, cities need to embrace a transformative adaptation approach to be better prepared to tackle growing climatic risks and other unsustainability concerns. 


\section{REFERENCES}

Revi, A., Satterthwaite, D., AragonDurand, F., Corfee-Morlot, J., Kiunsi, R.B., Pelling, M., Roberts, D., Solecki, W., Gajjar, S.P., Sverdlik, A.: Towards transformative adaptation in cities: The IPCC's Fifth Assessment. Environment \& Urbanasation, 26, 11-28 (2014).

Leichenko, R.: Climate change and urban resilience. Current Opinion in Environmental Sustainability, 3, 164-168 (2011).

Pelling, M. et al.,: Africa's urban adaptation transition under a $1.5^{\circ}$ climate. Current Opinion in Environmental Sustainability, 31, 10-15 (2018).

Satterthwaite, D., Archer, D., Colenbrander, S., Dodman, D., Hardoy, $\mathrm{J} .:$ Responding to climate change in cities and in their informal settlements and economies. International Institute for Environment and Development (IIED) and IIED-America Latina (2018).

Ziervogel, G., Cowen, A., Ziniades, J.: Moving from adaptive to transformative capacity: Building foundations for inclusive, thriving, and regenerative urban settlements. Sustainability, 8 (9), art. no. 955 (2016).

Pieterse, E., Simone, A.: Rogue urbanism: Emergent African cities; Jacana Media: Sunnyside, South Africa (2013).

Kayhko, J., Wirehn, L., Juhola, S., Neset, T.S. Integrated framework for identifying transformative adaptation in agri-food systems. Environmental Science and Policy, 114, 580-586 (2020).

Fedele, G., Donatti, C.I., Harvey, C.A., Hannah, L., Hole, D.G.: Limited use of transformative adaptation in response to social-ecological shifts driven by climate change. Ecology and Society, 25 (1), art. no. 25 (2020).
Chirisa, I., Bandauko, E.: African cities and the water-food-climate-energy nexus: an agenda for sustainability and resilience at a local level. Urban Forum (2015), DOI 10.1007/s12132-015-92566

Kareem, B., Lwasa, S., Tugume, D., Mukwaya, P., Walubwa, J., Owuor, S., Kasaija, P., Sseviiri, H., Nsangi, G., \& Byarugaba, D.: Pathways for resilience to climate change in African cities. Environmental Research Letters, 15, 073002 (2020). 
Notes 